\title{
AN EXERCISE TEST TO EVALUATE FITNESS FOR WHEELCHAIR ACTIVITY ${ }^{1}$
}

\author{
By Roger M. Glaser, Ph.D., Diane M. Foley, M.S., Lloyd L. Laubach, Ph.D., \\ Michael N. Sawka, Ph.D., and Agaram G. Suryaprasad, M. D. \\ Laboratory of Applied Physiology, Wright State University School of Medicine, and the \\ Physiology Research Laboratory, Veterans Administration Center, Dayton, \\ Ohio, 45435, U.S.A.
}

Abstract. The purpose of this study was to develop a wheelchair ergometer (WERG) test to evaluate fitness for manual wheelchair activity. Thirty able-bodied females participated in a progressive intensity, discontinuous test where exercise bouts were 4 min in duration interspersed with 5-min rest periods. Physiological responses of oxygen uptake $\left(\dot{\mathrm{VO}}_{2}\right)$, respiratory exchange ratio $(\mathrm{R})$, net mechanical efficiency $(\mathrm{ME})$, pulmonary ventilation $(\mathbf{V O})$ and heart rate $(\mathrm{HR})$ were determined during the final minute of exercise at power output (PO) levels of $30,60,90,120$ and $150 \mathrm{kpm} / \mathrm{min}$. These responses were generally found to be linearly related to $\mathrm{PO}$, however, net $\mathrm{ME}$ initially increased with PO and plateaued at approximately II per cent at $90 \mathrm{kpm} / \mathrm{min}$. Criteria for fitness evaluation were based upon: (I) magnitude of physiological responses at each PO level; and (2) the maximal PO level completed.

Key words: Wheelchair exercise testing; Physiological responses to wheelchair ergometer exercise; Fitness evaluation for wheelchair operation.

\section{Introduction}

MANY disabled people are dependent upon manually operated wheelchairs for their locomotion. Fitness to operate a wheelchair, however, may vary greatly due to one's disability(ies), muscular strength and endurance, cardiorespiratory capacity, and propulsion technique. For many patients, wheelchair locomotion may elicit excessive metabolic and cardiorespiratory stresses which could hinder rehabilitative efforts and impose potential health hazards (Engel and Hildebrandt, 1974; Fisher and Gullickson, 1978). The objective evaluation of one's ability to perform wheelchair activity would provide valuable information to physicians. This information may be used to prescribe wheelchairs, advise users as to their safe and effective operation, and allow evaluation of fitness changes over a period of time.

Currently, there are few well-established techniques to objectively evaluate an individual's fitness to perform wheelchair activity. Most fitness testing of wheelchair-dependent individuals has been performed using arm cranking of modified bicycle ergometers (Pollock et al., I974; Zwiren and Bar-Or, 1975). The concept of exercise specificity (McCafferty and Horvath, I977), however, suggests that meaningful evaluation of wheelchair performance requires wheelchairtype activity as the exercise mode. Wheelchair ergometry has been shown to be reliable and to simulate actual wheelchair locomotion (Glaser et al., 1977a). However, limited fitness testing has been conducted using these devices (Brattgård et al., 1970; Wicks et al., 1977-78; Glaser et al., 1978a). The purpose of this

${ }^{1}$ A portion of this work was presented at the Twenty-fifth Annual Meeting of the American College of Sports Medicine, Washington, D.C., 26 May I 978. 
study was to develop a wheelchair ergometer exercise test to evaluate fitness for manual wheelchair activity.

\section{Subjects}

\section{Methods}

Because of the developmental nature of this fitness evaluation test and instrumentation, as well as the variety of patient-types in wheelchairs, we decided to use able-bodied subjects for this study. Thirty able-bodied females volunteered to participate in this study. Their mean $( \pm S D)$ age was $21 \cdot 6 \pm 2.5$ years and body weight was $57 \cdot 0 \pm 7 \cdot 5 \mathrm{~kg}$. Each subject was informed as to the purpose of the study, their extent of involvement, any known risks, and their right to terminate participation at will. Each expressed understanding by signing a consent form. Subjects were then familiarised with the wheelchair ergometer and the instrumentation for physiological measurements.

\section{Wheelchair Ergometer}

Figure I illustrates the wheelchair ergometer (WERG) used in this study. This WERG is basically an extension of the popular Monark bicycle ergometer. Wheelchair wheels were mounted on a solid steel axle which was supported by low friction ball bearings. A chain and sprockets coupled this axle to the flywheel of the bicycle ergometer. Standard gearing of the Monark was retained so that

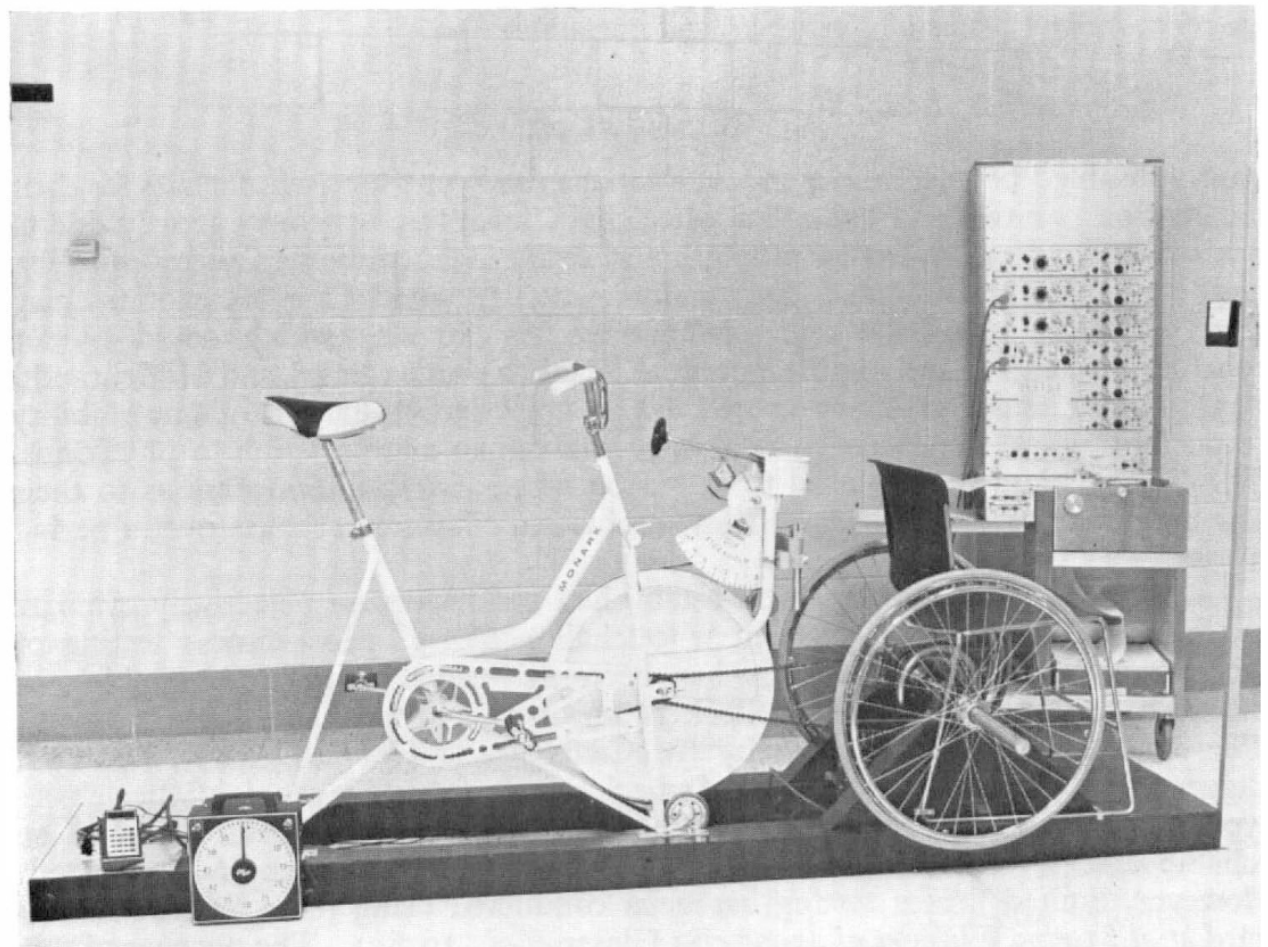

FIG. I

Wheelchair ergometer. 
for each wheelchair revolution, the flywheel travelled $6 \mathrm{~m}$. An electronic speedometer was used to measure wheelchair (and thus flywheel) velocity, and a wheel revolution counter allowed precise monitoring of the distance travelled over a period of time.

The standard flywheel friction belt was used, but because of the relatively low braking forces required for the WERG, the measuring scale was modified. For this, a force displacement transducer (Grass FT IO) was attached to the pendulum of the Monark force scale. An electrical recorder (Grass 7 B Polygraph) provided continuous braking force readings. We found it necessary to add a constant $0.025 \mathrm{kp}$ of force to all readings to account for the internal friction of the ergometer. Power output (PO) for the WERG was set in a similar manner as for the bicycle:

$$
\text { PO }(\mathrm{kpm} / \mathrm{min})=\text { braking force }(\mathrm{kp}) \times \text { flywheel velocity }(\mathrm{m} / \mathrm{min}) .
$$

\section{Physiological Variables}

Oxygen uptake $\left(\dot{\mathrm{VO}}_{2}, 1 / \mathrm{min}, \mathrm{STPD}\right)$, carbon dioxide output $\left(\dot{\mathrm{VCO}}_{2}, 1 / \mathrm{min}\right.$, STPD), respiratory exchange ratio $\left(\mathrm{R}, \dot{\mathrm{V}} \mathrm{CO}_{2} / \mathrm{VO}_{2}\right)$, and pulmonary ventilation (VE, l/min, BTPS) were calculated from data obtained by open circuit spirometry. Subjects inspired ambient air through a breathing valve (Collins 'Triple J'). At specified times, expired gases were collected in I2O-1 meteorological balloons. Two-litre aliquots were then analysed for oxygen concentration by a polarographic $\mathrm{O}_{2}$ analyser (Beckman OM-I I), and carbon dioxide concentration by an infrared $\mathrm{CO}_{2}$ analyser (Beckman LB-2). Expired gas volume (ATPS) was measured by a dry gasometer (Parkinson-Cowan CD-4) modified for digital readout. Per cent net mechanical efficiency ( $\mathrm{ME}$ ) was determined using the traditional computation of:

$$
\% \mathrm{ME}=W / E-e \times \mathrm{IOO}
$$

where $W$ is the caloric equivalent of external work performed $E$, the gross caloric output, and $e$ the resting caloric output. The caloric outputs of substrates utilised have been determined from the $\mathrm{VO}_{2}$ and $\mathrm{R}$ (Gaesser and Brooks, 1975).

The electrocardiogram was recorded on the polygraph from chest electrodes, and heart rate (HR) was continuously monitored by a cardio-tachometer (Gedco CT-2).

\section{Test Protocol}

Prior to exercise, subjects sat quietly on the WERG for 15 min. Resting physiological data were collected during the final 5 min. A progressive intensity, discontinuous test was used where WERG PO levels were 30, 60, 90, I 20 and I 50 $\mathrm{kpm} / \mathrm{min}$. For this, subjects maintained a velocity of $3.5 \mathrm{~km} / \mathrm{hr}$ (30 wheel revolutions per minute) and braking forces were set to $0.164,0.33 \mathrm{I}, 0.497,0.664$ and $0.83 \mathrm{I} \mathrm{kp}$, respectively. Exercise at each PO was $4 \mathrm{~min}$ in duration interspersed with 5-min rest periods. During the final minute of each exercise period, physiological data were collected. Exercise was terminated by either: (I) physical exhaustion; (2) attainment of 80 per cent of age adjusted maximal HR; or (3) completion of the $150 \mathrm{kpm} / \mathrm{min}$ level.

\section{Statistical Analysis}

Means, standard deviations and Pearson product correlation coefficients were calculated using a programmable calculator (Hewlett-Packard 98 I5A). Based on the inverse relationship between $\mathrm{HR}$ and fitness during submaximal 
exercise (Åstrand, I960; Morgan and Bennett, I976), normative data were established. Five fitness classifications (each comprising $I \cdot 2$ standard deviations) were computed at each PO level using statistical methods described by Mathews (I978).

\section{Results}

All 30 subjects were able to complete WERG exercise levels of 30, 60, and 90 $\mathrm{kpm} / \mathrm{min}$, whereas 29 and 24 subjects completed 120 and $150 \mathrm{kpm} / \mathrm{min}$, respectively. Figure 2 presents the $\mathrm{VO}_{2}, \mathrm{R}$ and net $\mathrm{ME}$ responses to WERG exercise at these PO levels. $\mathrm{VO}_{2}$ and $\mathrm{R}$ were found to increase linearly with PO. Net
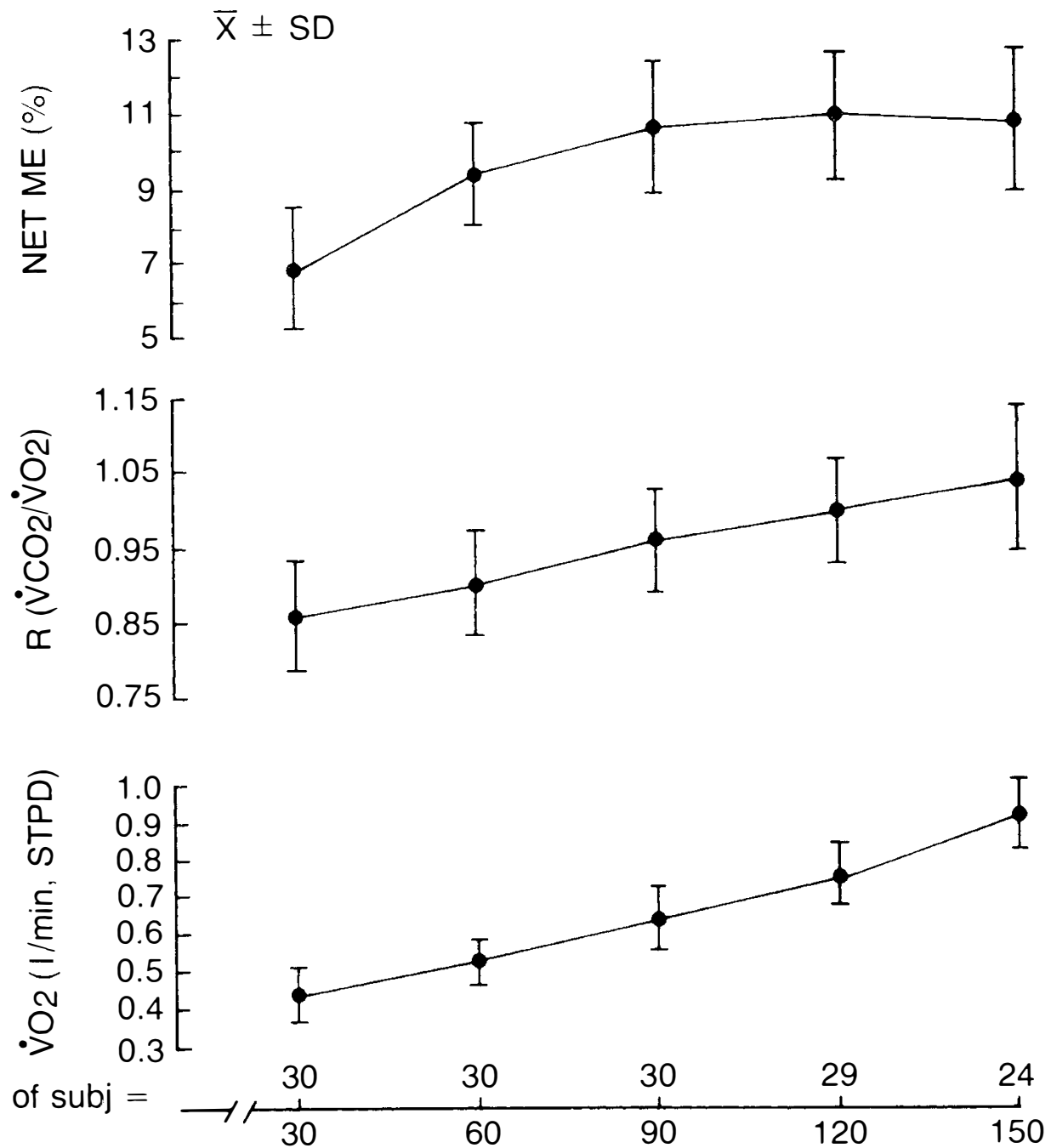

POWER OUTPUT $(\mathrm{kpm} / \mathrm{min})$

FIG. 2

Oxygen uptake, respiratory exchange ratio and net mechanical efficiency responses to wheelchair ergometer activity. 
ME initially increased with PO and 'plateaued at approximately I I per cent at $90 \mathrm{kpm} / \mathrm{min}$. Figure 3 depicts the $\mathrm{VE}$ and $\mathrm{HR}$ responses which were also found to be linear with respect to PO. The slope of the VE-PO relationship, however, tended to increase at higher PO levels. The range for each physiological variable at each PO level is presented in Table I. These data illustrate the highest and lowest responses that were observed during WERG exercise.

Table II presents fitness norms that were derived from the subjects' HR responses at given PO levels on the WERG. Five fitness classifications were
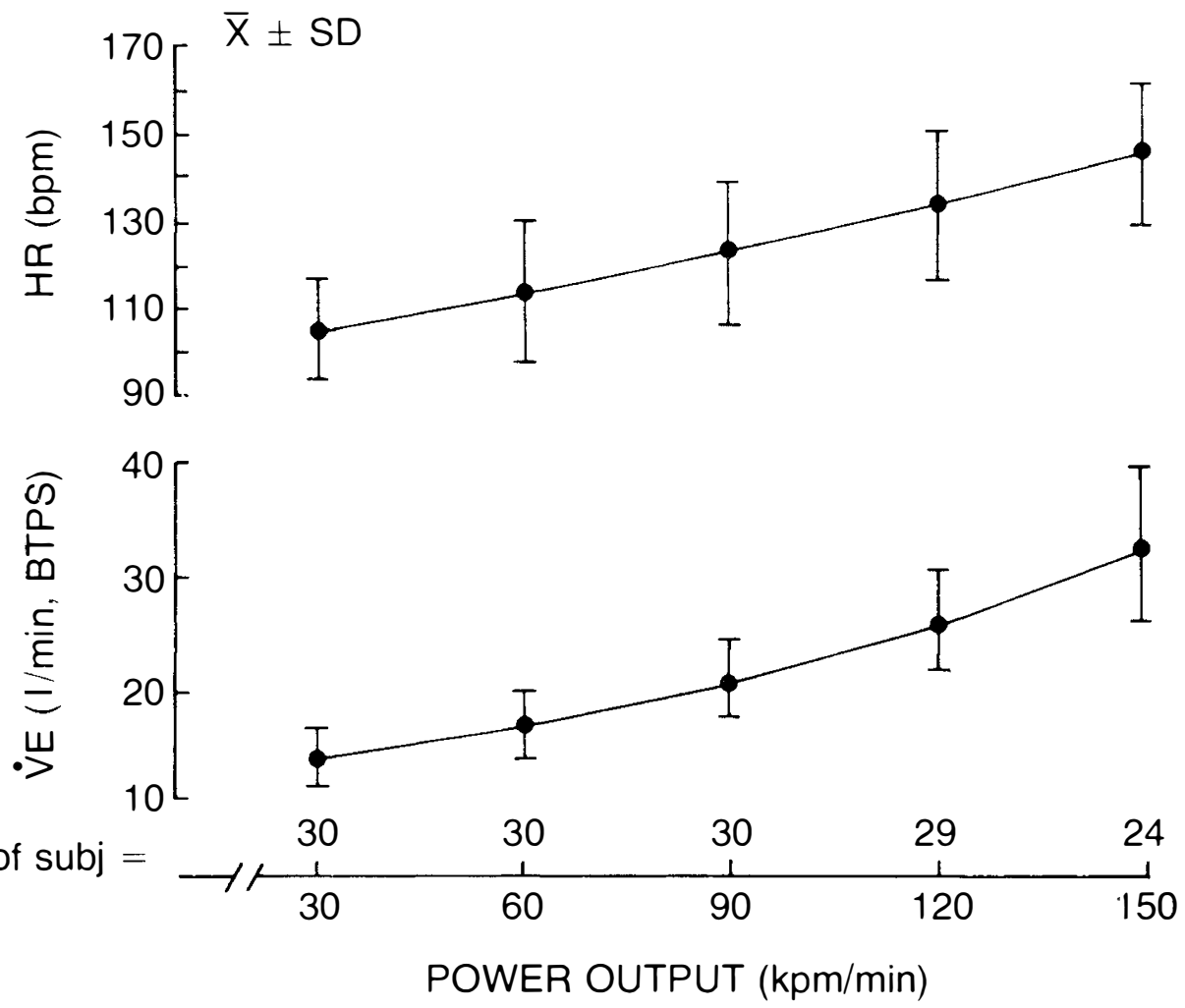

FIG. 3

Pulmonary ventilation and heart rate responses to wheelchair ergometer activity.

\section{TABLE I}

Range for physiological variables at each power output level

\begin{tabular}{|c|c|c|c|c|c|}
\hline & \multicolumn{5}{|c|}{ Power output $(\mathrm{kpm} / \mathrm{min})$} \\
\hline & 30 & 60 & 90 & 120 & I 50 \\
\hline & $\max$ & $\max$ & $\max$ & $\max$ & $\min$ \\
\hline$\dot{\mathrm{VO}}_{2}(1 / \mathrm{min}, \mathrm{STPD})$ & $0.338-0.559$ & $0.409-0.639$ & $0.446-0.747$ & $0.583-0.880$ & $0.674-I .062$ \\
\hline $\begin{array}{l}\mathrm{R}\left(\mathrm{VCO}_{2} / \mathrm{VO}_{2}\right) \\
\mathrm{ME}\left(0_{0}^{\prime}\right)\end{array}$ & $\begin{array}{l}0.73-1 \cdot 01 \\
4.62-10 \cdot 60\end{array}$ & $\begin{array}{l}0.78-1.03 \\
7 \cdot 19-12 \cdot 04\end{array}$ & $\begin{array}{l}0.81-1 \cdot 16 \\
8 \cdot 07-15.26\end{array}$ & $\begin{array}{l}0 \cdot 86-\mathrm{I} \cdot \mathrm{I} 4 \\
8 \cdot 40-\mathrm{I} 6 \cdot 06\end{array}$ & $\begin{array}{l}0.90-\mathrm{I} \cdot 27 \\
8 \cdot 24-\mathrm{I} 5 \cdot 84\end{array}$ \\
\hline $\begin{array}{l}\text { VE (1/min, BTPS) } \\
\text { HR (beats/min) }\end{array}$ & $\begin{array}{c}10 \cdot 16-19 \cdot 99 \\
76-136\end{array}$ & $\begin{array}{c}\text { II } 65-22 \cdot 58 \\
74-144\end{array}$ & $\begin{array}{c}14 \cdot 13-3 I \cdot 33 \\
8 I-168\end{array}$ & $\begin{array}{c}19 \cdot 78-35 \cdot 85 \\
94-170\end{array}$ & $\begin{array}{c}21 \cdot 26-48 \cdot 38 \\
102-172\end{array}$ \\
\hline
\end{tabular}




\section{TABLE II}

Classifications of fitness to use a manual wheelchair based upon heart rate responses

\begin{tabular}{|c|c|c|c|c|c|}
\hline \multirow[t]{2}{*}{ Classification } & \multicolumn{5}{|c|}{ Power output $(\mathrm{kpm} \min )$} \\
\hline & 30 & 60 & 90 & 120 & 150 \\
\hline & - & $\ldots$ & & & $\ldots \ldots$ \\
\hline Excellent & $<83$ & $<86$ & $<94$ & $<\mathrm{IO} 4$ & $<\mathrm{II} 7$ \\
\hline Good & $83-96$ & $86-103$ & $94-$ I I 3 & $104-123$ & I I $7-136$ \\
\hline Average & $97-$ I I I & IO4-I II & II $4-133$ & I $24-I 44$ & I $37-157$ \\
\hline Low-Average & I I $2-125$ & I 22-I39 & $134-153$ & I $45-164$ & I 58-I 77 \\
\hline Poor & $>125$ & $>139$ & $>153$ & $>164$ & $>177$ \\
\hline
\end{tabular}

TABLE III

Correlation matrix among heart rate responses to wheelchair ergometer exercise

\begin{tabular}{ccccccc}
\hline $\begin{array}{c}\text { Power output } \\
(\mathrm{kpm} / \mathrm{min})\end{array}$ & 60 & 90 & $\mathrm{I} 20$ & $\mathrm{I} 50$ & \\
& & & & & & \\
30 & 0.93 & 0.83 & 0.76 & 0.62 & & \\
60 & & 0.92 & 0.85 & 0.70 & \\
90 & & & 0.92 & 0.87 & & \\
120 & & & 0.93 & \\
\hline
\end{tabular}

computed for each PO. An intercorrelation matrix of the subjects' HR responses to each PO is presented in Table III. These correlations were all significant at the $p<0.001$ level.

\section{Discussion}

The WERG provided an exercise mode that was related to the actual locomotor task encountered by wheelchair-dependent patients. The presented WERG fitness test used PO levels ranging from 30 to $150 \mathrm{kpm} / \mathrm{min}$. Previous research indicated that $30 \mathrm{kpm} / \mathrm{min}$ is the approximate $\mathrm{PO}$ necessary for a $70 \mathrm{~kg}$ individual to operate a manual wheelchair at $3.5 \mathrm{~km} / \mathrm{hr}$ over a smooth level surface (Glaser and Chao, 1976). Locomotion up an incline or on floor surfaces which offer greater rolling resistance, such as carpeting, would increase the PO requirement. From previous research, I $50 \mathrm{kpm} / \mathrm{min}$ was considered to be a reasonable upper limit for this test (Barr and Glaser, I977). At this PO, the present subjects achieved approximately 75 per cent of their age adjusted maximal HR, had disproportionately elevated $\mathrm{VE}$, and an $\mathrm{R}$ value exceeding unity. The magnitude of these physiological responses indicated that the subjects were engaged in heavy exercise. This terminal PO for the WERG fitness test, however, was quite low in comparison to those associated with leg exercise.

The progressive intensity, discontinuous protocol used in conjunction with the WERG appeared suitable for the clinical evaluation of patient fitness to use a wheelchair. Physiological data were collected during the fourth minute of WERG exercise to obtain steady state values. The 5-min rest periods following bouts 
of exercise were used to allow time for recovery of the subjects. Criteria for fitness evaluation were based upon: (I) magnitude of physiological responses at each PO level; and (2) the maximal PO level completed.

Physiological responses to a specific submaximal exercise task are commonly considered to be inversely related to one's fitness to perform that activity-the higher responses, the lower the fitness. Based on the interindividual variability of metabolic and cardiorespiratory responses to the WERG exercise test, these subjects exhibited a wide range of wheelchair operating ability. This may be due, in part, to their unfamiliarity with this upper-body activity, as well as differences in their muscular strength, endurance and cardiorespiratory capacity.

For a given $\mathrm{PO}$, variability in $\mathrm{VO}_{2}$ responses, and thus $\mathrm{ME}$, may be indicative of individual operating techniques (Engel and Hildebrandt, I973; Glaser et al., 1977b; Wicks et al., 1977-78). Since ME is the ratio of PO accomplished to the aerobic energy expenditure, it provides an objective index of the effectiveness of one's propulsion biomechanics. Improved propulsion skills would be expected to increase $\mathrm{ME}$ and thereby reduce the absolute metabolic cost and the related cardiorespiratory responses. These effects have been demonstrated with extensive wheelchair practice (Engel and Hildebrandt, I973; Glaser et al., I978b).

The magnitude of $\mathrm{R}, \mathrm{VE}$, and $\mathrm{HR}$ responses for WERG exercises at a given PO provides indices of relative stress encountered. Individuals exhibiting lower responses would be expected to possess greater metabolic and cardiorespiratory reserve. Therefore, individuals of low fitness levels would be working at a greater percentage of their maximal capacity. For the unfit, energy demands readily tax their aerobic system, elevating $\mathrm{HR}$, and an increased anaerobic energy component may be required for work to continue. Elevated $\mathrm{R}$ and $\dot{\mathrm{V}} \mathrm{E}$ responses have been associated with lactic acid production during anaerobic metabolism (Bouhuys et al., 1966; Koyal et al., 1976).

As specialised instrumentation and techniques are required for the determination of $\mathrm{VO}_{2}, \mathrm{R}$ and $\dot{\mathrm{VE}}$, these variables may not be practical for clinical testing. HR-PO relationships and the maximal PO level completed, however, are two easily obtained variables that provide information concerning one's fitness for wheelchair locomotion. Submaximal HR-PO relationships have been widely used as an indirect indicator of metabolic stress and cardiorespiratory capacity (Astrand, I960; Morgan and Bennett, I976). WERG fitness classifications, as presented (Table II) may be developed for various patient populations. Maximal PO level completed during the WERG test provides information on the muscular strength and endurance components of fitness. As wheelchair propulsion involves the relatively weak upper-body musculature, local arm fatigue rather than cardiorespiratory factors may limit one's ability to operate a manual wheelchair (Voigt and Bahn, I969; Hjeltnes, I977).

The female subjects in this study were able-bodied, and therefore, acutely exposed to wheelchair operation. The physiological responses to WERG exercise for chronic wheelchair patients may be quite different. In using this WERG test in rehabilitation medicine, standards could be developed for various wheelchair patient populations. It is hoped that the techniques presented in this paper will facilitate fitness evaluation of wheelchair-dependent patients.

\section{RÉSUMÉ}

Le but de cette étude était de développer une épreuve des ergomètres des fauteuils roulants (WERG) afin d'évaluer leur convenabilité aux activités des faureuils roulants manuels. Trente femmes robustes ont participé à une épreuve discontinue $d^{\prime}$ intensite progressive 
dans laquelle les tours d'exercice duraient quatres minutes et étaient entremêlés des périodes de repos durant cinq minutes. L'on a détérminé les réactions physiologiques de la fixation d'oxygène $\left(\mathrm{VO}_{2}\right)$, le rapport de l'echange respiratoire $(\mathrm{R})$, l'éfficacité méchanique nette (ME), la ventilation pulmonaire (VE), et la fréquence cardiaque (HR) pendant la minute finale d'exercice aux niveaux des rendements de puissance de 30,60,90, I20, et I $50 \mathrm{kpm} / \mathrm{min}$. L'on a constaté que ces réactions, en général, étaient en relation linéaire avec le PO; cependant, la ME nette s'est initialement augmentée avec le $\mathrm{PO}$ et elle s'est nivelée à environ I I \% à $90 \mathrm{kpl} / \mathrm{min}$. L'on a basé les critères de l'évaluation de la convenabilité sur: (I) l'importance des réactions physiologiques à chaque niveau; et (2) le niveau maximal du PO achevé.

\section{ZUSAMMENFASSUNG}

Der Zweck dieser Forschung war einen Rollstuhl-Ergometer-Test (WERG) zu entwickeln, um die Eignung für Rollstuhl-Activität mit Handantrieb abzuschätzen. Dreissig ganz gesunde Frauen nahmen in einem unterbrochenen Test mit steigender Intensität teil, wobei die vierminutigen Aktivitätsgänge mit fünfminutigen Erholungsperioden durchgesetzt wurden. Physiologische Reaktionen wie Sauerstoffaufnahme $\left(\mathrm{VO}_{2}\right)$, Atmungsquotient $(\mathrm{R})$, gesamt mechanischer Wirkungsgrad (ME), Lungenventilation ( $\dot{V} E)$ und Herzrate (HR) wurden während der letzten Minute der Aktivität mit Leistungsabgabenhöhen von 30, $60,90,120$ und $150 \mathrm{kmp} / \mathrm{min}$ bestimmt. Im allgemeinen befanden sich diese Reaktionen in einem linearen Verhältnis zu PO; jedoch, netto ME stieg mit PO an und wurde eben auf ca. II \% bei $90 \mathrm{kmp} / \mathrm{min}$. Kriterien für Eignungsabschätzung basierten sich auf: (I) die Grösse der Reaktionen bei jeder Höhe; und (2) die maximale gefertigte PO-Höhe.

Acknowledgements. This study was supported by the Medical Research Service of the Veterans Administration and the American Heart Association, Miami Valley Heart Chapter. The authors wish to thank Mr Stephen A. Barr and Dr Richard D. Burk for their assisatance. Recognition is also due to $\mathrm{Mr}$ John Ferraro who prepared the illustrations.

\section{REFERENCES}

Åstrand, I. (1960). Aerobic work capacity in men and women-with special reference to age. Acta Physiol. Scand., Suppl., I69, 49, 9-92.

BARR, S. A. \& Glaser, R. M. (1977). Physiological responses to wheelchair and bicycle activity. Fed. Proc., 36, 580 .

Bounuys, A., Pool, J., Binkhorst, R. A. \& van Leeuwen, P. (I966). Metabolic acidosis of exercise in healthy males. F. Appl. Physiol., 21, I040-I045.

BrattGård, S.-O., Grimby, G. \& HööK, O. (I970). Energy expenditure and heart rate in driving a wheel-chair ergometer. Scand. F. Rehabil. Med., 2, I43-I48.

ENGEL, P. \& HILDEBRANDT, G. (I 973). Long-term spiroergometric studies of paraplegics during the clinical period of rehabilitation. Paraplegia, II, IO5-I IO.

Engel, P. \& Hildebrandt, G. (1974). Wheelchair design-technological and physiological aspects. Proc. Roy. Soc. Med., 67, 409-4I3.

Fisher, S. V. \& Gullickson, JR., G. (1978). Energy cost of ambulation in health and disability: a literature review. Arch. Phys. Med. Rehabil., 59, I24-1 33.

GAESSER, G. A. \& BROOKS, G. A. (I975). Muscular efficiency during steady-rate exercise: effects of speed and work rate. F. Appl. Physiol., 38, I I 32-I I 39.

Glaser, R. M. \& ChaO, A. Y. (1976). Power output and energy cost of wheelchair ambulation. Fed. Proc., 34, 529.

Glaser, R. M., Ginger, J. F. \& LAubach, L. L. (I977a). Validity and reliability of wheelchair ergometry. Physiologist, 20, 34 .

Glaser, R. M., Young, R. E., \& Suryaprasad, A. G. (1977b). Reducing energy cost and cardiopulmonary stresses during wheelchair activity. Fed. Proc., 36, 580.

Glaser, R. M., Bolduc, S. P., Laubach, L. L. \& Suryaprasad, A. G. (I978a). A cardiopulmonary fitness test utilizing the wheelchair ergometer. Fed. Proc., 37, 429.

Glaser, R. M., Laubach, L. L., Foley, D. M., Barr, S. A., Suryaprasad, A. G. \& Burk, R. D. (1978b). An interval training program for wheelchair users. Med. Sci. Sports, I0, 54 .

HJELTNES, N. (1977). Oxygen uptake and cardiac output in graded arm exercise in paraplegics with low level spinal lesion. Scand. F. Rehail. Med., 9, I07-I I3. 
Koyal, S. N., Whipp, B. J., Huntsman, D., Bray, G. A. \& Wasserman, K. (I976). Ventilatory responses to the metabolic acidosis of treadmill and cycle ergometry. F. Appl. Physiol., 40, 864-867.

Mathews, D. K. (1978). Measurement in Physical Education, 5th ed, pp. 82-83. Saunders, Philadelphia.

MCCAFFERTY, W. R. \& HoRvath, S. M. (I977). Specificity of exercise and specificity of training: a subcellular response. Res. Q. Am. Assoc. Health Phys. Educ., 48, 358-37I.

Morgan, D. B. \& BeNNET, T. (1976). The relation between heart rate and oxygen consumption during exercise. $\mathcal{F}$. Sports Med. Phys. Fitness, 16, 38-44.

Pollock, M. L., Miller, H. S., Linnerud, A. C., Laughridge, E., Coleman, E. \& ALEXANDER, E. (1974). Arm pedaling as an endurance training regimen for the disabled. Arch. Phys. Med. Rehabil., 55, 4I8-42I.

Voigt, E.-D. \& BAHN, D. (I969). Metabolism and pulse rate in physically handicapped when propelling a wheel chair up an incline. Scand. F. Rehabil. Med., I, IOI-IO6.

Wicks, J. R., Lymburner, K., Dinsdale, S. M. \& Jones, N. L. (I977-78). The use of multistage exercise testing with wheelchair ergometry and arm cranking in subjects with spinal cord lesions. Paraplegia, 15, 252-261.

ZWIREN, L. D. \& BAR-OR, O. (I975). Responses to exercise of paraplegics who differ in conditioning level. Med. Sci. Sports, 7, 94-98. 